\title{
LOS PROCESOS DE NORMALIZACION, ARMONIZACION Y COMPATIBILIZACION EN EL MERCOSUR: IMPACTOS EN EL SECTOR INFORMACION
}

\author{
Mario Barité
}

\begin{abstract}
Resumo
Caracteriza e resenha a existência do Mercosul até o presente e, em particular, discute a idéia de um «Mercosul da Informação» que compreenda aspectos de políticas de transferência, intercâmbio e acesso à informação. Determina o conceito de «normalização» no marco do projeto de integração econômica, política, social e cultural implícito na criação e desenvolvimento do Mercosul, e o analisa com as noções de "harmonização», compatibilização», "correspondência» e "equivalência». Discorre sobre a produção de bens e serviços de informação e sobre as modalidades possíveis de integração de políticas, sistemas e redes de informação. Destaca o aporte da terminologia como instrumento de primeira ordem para interagir nas questões de comércio, indústria, ciência e cultura envolvidas no desenvolvimento regional. Por último, propõe recomendações que contribuam para o desenvolvimento de políticas regionais de informação.
\end{abstract}

\section{Palavras-Chave}

Normalização; Transferência de Informação; Acesso à Informação; Mercosul; Terminologia.

\section{INTRODUCCION AL MERCOSUR}

Quiero agradecer la deferencia que han tenido algunos amigos, y en particular
Marta Valentim, en invitarme a participar de este Simposio, con la idea - que espero no defraudar - de que podía aportar una mirada significativa sobre los fenómenos de la 
información en el Mercosur. También me congratulo de compartir este panel con Hagar Espanha, con quien me reencuentro aquí, una personalidad distinguida y una referencia en nuestra profesión. Por último, quiero dar cuenta de la hospitalidad recibida, hospitalidad que siempre es una forma delicada del afecto.

Me ha tocado en suerte hablar en este panel sobre «Mercosur versus Normalización: integración para el desarrollo». Mi acercamiento a algunos de estos temas se há dado por el desarrollo de trabajos y proyectos de investigación vinculados directamente a la Terminología, y a los problemas de correspondencia y comunicación de información especializada entre las lenguas española y portuguesa. Debo confesar que el nombre del panel me ofreció algunas dificultades conceptuales y, justamente, terminológicas. En efecto, no veía por qué debían aparecer presuntamente enfrentados un concepto macroeconómico y supranacional como Mercosur, con otro concepto de orden abstracto, como la normalización. Por otra parte, me pareció adecuado precisar lo que entendemos por «normalización» en el contexto de esta palestra, y relacionar ese término con las nociones no menos importantes de «compatibilización», «armonización», «correspondencia» y «equivalencia».

Por cierto, las temáticas involucradas son muy amplias, complejas, en pleno proceso de desarrollo e interacción, lo que hace muy difícil encontrar la perspectiva justa para su análisis, y su adecuada presentación en el tiempo de que disponemos.

Ante todo, ¿por qué y para qué MERCOSUR? Esta pregunta conserva su vigencia a más de siete años de la firma del Tratado de Asunción, pues si bien se han logrado avances realmente extraordinarios en el proceso de integración, no es menos real que con cierta frecuencia aparecen agoreros y escépticos que cuestionan su viabilidad futura, o los beneficios que puedan surgir de la misma. Los fenómenos de globalización y de regionalización que se materializan, por una parte, en el desarrollo de una aldea global sustentada tecnológicamente, y por el otro, en la formación de grandes bloques políticoeconómicos, son el retrato hablado del sistema económico internacional a fines de este siglo. El mango de la sartén de este proceso está en manos de aquellas regiones de mayor dinamismo en lo que hace al desarrollo científico-tecnológico y económico (esencialmente Estados Unidos, la Unión Europea y Japón), al punto que el $70 \%$ del comercio mundial y el $80 \%$ de las inversiones extranjeras se establece entre esos centros económicos. Desde allí se regulan hacia el todo el mundo las corrientes de intercambio comercial, los procesos de transferencia de tecnología y el destino de los recursos financieros internacionales. (Mellado, p.158)

Estos fenómenos se dan en un mundo fuertemente desequilibrado desde el punto de vista económico, y por ende, en los 
niveles de desarrollo científico-tecnológico y de la calidad de vida; un mundo jaqueado tanto por cuestiones de incidencia universal como el deterioro del medio ambiente, como por problemáticas sociales de difícil resolución (desempleo, pobreza, analfabetismo tecnológico, etc.).

Las naciones menos favorecidas en esta realidad se han visto obligadas a imaginar nuevas estrategias, ya de superviviencia, ya de acomodamiento a las nuevas reglas internacionales. Por ello han debido aceptar la imposición de reformas estructurales de sus aparatos de Estado (reduciéndolos), y de sus sistemas económicos internos, preparándolos para la especialización dentro del mercado mundial, que termina actuando como elemento homogeneizante de las sociedades y sus economías. En este contexto particularmente agresivo, parece casi natural el desarrollo de algunas experiencias de integración subregional, para enfrentar estas realidades fortalecidos hacia afuera del bloque, y regulados por normas flexibles $y$ consensuadas hacia adentro de la región.

Si observamos todos los laboratorios de integración que se dan entre los países más afectados por la asimetría económica y por el proteccionismo y el poder financiero $y$ tecnológico de los países del primer mundo, acreditamos que el Mercosur es el más feliz de los emprendimientos, y el que ha demostrado en siete años de desarrollo, «anche» tres o cuatro crisis internas que fueron rápidamente negociadas y superadas, un proceso ininterrumpido de avance, más allá de los objetivos primariamente económicos y arancelarios.

Es perceptible para todos nosotros, habitantes "mercosurianos», que hay un antes y un después del Tratado de Asunción de 1991, y que afortunadamente no podemos decir, como en una frase popular brasileña, que «tudo vai como dantes no quartel de Abrantes».

Los especialistas distinguen cuatro tipos distintos de integración:

a) AREA DE PREFERENCIA ARANCELARIA: es el más sencillo y sólo comprenden a cuestiones arancelarias. En este caso, los Estados socios gravan al comercio recíproco (en todo o en parte) con impuestos inferiores a los que tributan las mercaderías de terceros países.

b) ZONA DE LIBRE COMERCIO: en un estadio mayor de avance los Estados socios eliminan las trabas arancelarias de cualquier especie para favorecer el comercio recíproco.

c) UNION ADUANERA: como forma más evolucionada, y todavía dentro de los acuerdos de mero interés económico, al libre comercio entre los Estados socios, se suma la adopción de un arancel externo común frente a terceros países.

d) MERCADO COMUN: es la forma más avanzada de integración, pues a la unión 
aduanera se suman la libre movilidad y circulación de factores productivos entre los países miembros bajo una política comercial exterior común. El desarrollo de un mercado común implica necesariamente la coordinación de políticas macroeconómicas y sectoriales entre los miembros, la armonización de legislaciones nacionales y la generación de normativas regionales obligatorias, y la incorporación de proyectos de integración en el orden social y cultural que impidan que el proyecto económico gire en el vacío. Por esta vía puede llegarse, con el tiempo, a una confederación de Estados (al modo de los Estados Unidos), o a similares caracterizaciones políticas. (Arbuet, p. 36)

El Mercosur (o Mercado Común del Sur) aspira a esta última modalidad de integración, expuesta desde el artículo $1^{\circ} \mathrm{del}$ Tratado de Asunción que propone:

«- la libre circulación de bienes, servicios y factores productivos entre los países...».

«- el establecimiento de un arancel externo común y la adopción de una política comercial común con relación a terceros Estados o agrupaciones de Estados, y la coordinación de posiciones en foros económico-comerciales...»

«- la coordinación de políticas macroeconómicas y sectoriales entre los Estados Partes», mencionando a continuación una larga serie de áreas de actividad involucradas, como políticas

\section{INTEGRACION, SOCIEDAD E INFORMACION}

Existe entonces la voluntad expresa de los cuatro socios del Mercosur, de darle un alcance amplio al término «integración», llevándolo a los espacios económicos, políticos, sociales y culturales. Pero no hay proceso de integración real en todos estos niveles si el mismo no cuenta con una «amplia participación social que involucre no sólo a los integradores, que son algunos, sino a los integrados -que somos todos los habitantes de la región-» (Laredo, p. 178). La idea de Mercosur, creemos, removió un magma, una sustancia esencial que está presente en la información genética de nuestros pueblos, respecto a la construcción de una gran patria americana, cuyo ideario está presente en el pensamiento de nuestros héroes y pensadores, como Martí, Artigas o Bolívar.

Hemos vivido de espaldas mucho tiempo, mirando hacia adentro de nuestras fronteras o en sentidos unidireccionales. Uruguay, por ejemplo, tiene una tradición histórica muy fuerte de intercambio con Buenos Aires y las provincias limítrofes de la Argentina, antes que con los Estados sureños del Brasil (Río Grande do Sul, 
Paraná y Santa Catarina). Para ello ha incidido naturalmente la frontera lingüística; pero también, y no menos, el desconocimiento recíproco de nuestras identidades sociales y culturales. Hoy ese muro de Berlín levantado hace siglos por los imperios españoles, portugueses e ingleses ha comenzado a derrumbarse. Sobre los escombros de ese muro se está empezando a construir lentamente una nacionalidad, una mentalidad y un sentimiento de pertenencia mercosuriano. Como señala Klor (1996), «la integración no es un fenómeno ajeno a los ciudadanos, y en la medida que se va avanzando en ella afecta muy directamente las ideas, los principios, las creencias y los intereses de cada uno de los individuos».

Hasta ahora, sin embargo, tenemos la impresión de que el Mercosur ha evolucionado especialmente a nivel de gobiernos y empresarios. Las primeras interfases que salen de ese marco se han dado en algunos sectores de impacto social. Respecto a la educación, por ejemplo, desde el año 1994 se han aprobado actas y protocolos que tienen directa incidencia sobre la armonización, la compatibilización y el régimen de revalidaciones en todos los niveles de la educación formal.

Desde el exterior el bloque Mercosur es visto con respeto creciente, y se sorprenden -sobre todo- de que dos potencias del tercer mundo como Brasil y Argentina, históricamente enfrentadas, hayan podido coincidir en un proyecto común de tales dimensiones.
Claro que los cuatro países han tenido que pagar y pagan costos en lo interno (reconversión industrial, desempleo, etc.) para fortalecer este proyecto de integración que permita un protagonismo real en el orden internacional. Por otra parte, el proceso interno de regulación del Mercosur no ha estado exento de dificultades. La integración exige mecanismos institucionales coadministrados y consensuados, libres de toda sospecha. En este estado intermedio de desarrollo todavía los Estados Parte están obligados a actuar por consenso y cada país mantiene su derecho al veto; así también, la formulación de un régimen de solución de controversias entre las partes no ha evolucionado hacia la obligatoriedad de las instancias jurisdiccionales y de la aplicación de sus sentencias, a la creación de un Tribunal de Justicia permanente y no ad hoc como al presente, y a una interpretación uniforme del derecho comunitario. Y ello es así porque todavía están en desarrollo los marcos jurídicos e institucionales más idóneos.

Muy brevemente, veamos la actual estructura orgánica del Mercosur, de caracter transitorio. Se integra así:

\section{CONSEJO DEL MERCADO COMUN} $(\mathrm{CMC})$ : Es el órgano superior del Mercosur, al cual compete la conducción política del proceso de integración y la toma de decisiones para asegurar el cumplimiento de los objetivos establecidos. Lo integran los Ministros de Relaciones Exteriores y de Economía. Sus decisiones son obligatorias. 
2. GRUPO MERCADO COMUN (GMC): Es el órgano ejecutivo del Mercosur, y se integra con representantes de los Ministerios de Relaciones Exteriores y de Economía o equivalentes, y de los Bancos Centrales de cada país.

3. COMISION DE COMERCIO DEL MERCOSUR (CCM): este órgano asiste al GMC en lo relativo a la aplicación de los instrumentos de política comercial común, el análisis y seguimiento de dicha política, y lo relacionado con el comercio intraMercosur y con terceros países.

4. COMISION PARLAMENTARIA CONJUNTA (CPC): es el órgano representativo de los Parlamentos o Congresos de los Estados Parte. Juega como nexo entre el Mercosur y los respectivos Poderes Legislativos, y contribuye a que los países miembros sancionen con leyes nacionales las normas emanadas de los órganos del Mercosur.

\section{FORO CONSULTIVO ECONOMICO Y} SOCIAL (FCES): órgano de representación de los sectores económicos y sociales (especialmente empresarios y trabajadores), que tiene una función consultiva y puede hacer recomendaciones al Grupo Mercado Común. Se espera que tenga particular importancia en la formulación de políticas sociales y laborales a nivel regional.

6. SECRETARIA ADMINISTRATIVA DEL MERCOSUR (SAM): es por fin, el órgano de apoyo operativo, responsable de la prestación de servicios a los demás órganos

del Mercosur.

\section{3 ¿HACIA UN MERCOSUR DE LA INFORMACION?}

Los fenómenos de la información son muy complejos, y a la manera de un poliedro, tienen muchas aristas que se entrecruzan y no siempre son fáciles de delimitar. En lo que hace al Mercosur, parecen tan importantes aspectos vinculados a la generación y al registro de conocimiento e información, como la identificación de las fuentes y los tipos de información más relevantes, los grupos de usuarios y sus necesidades, la identificación de los sistemas o bancos de información en temáticas afines, o los procesos de intercambio, transferencia y tráfico de información.

No parece posible alcanzar la libre circulación de bienes, servicios y factores productivos en la región, sin la incorporación de un sistema de comunicaciones fluido y moderno, y de sistemas y unidades de información tecnológica y conceptualmente avanzados. Por una parte, los parámetros de calidad exigibles a nivel internacional para la producción de bienes y servicios obligan a las empresas, los gobiernos y sus dependencias, los profesionales y los usuarios, a disponer de fuentes, canales y servicios de información actualizados, fiables y de acceso global. Por otro lado, la magnitud del intercambio comercial, el volumen de comunicaciones necesario para efectivizarlo (gestión, negociación, contratación,

\footnotetext{
Inf.Inf., Londrina, v. 5, n. 1, p. 43-60, jan./jun. 2000
} 
tramitación, entrega y recibo de mercaderías, pago, etc.) requiere de infraestructuras apropiadas para favorecer el intercambio de información sobre bienes y personas. Las Universidades parecen ser las otras instituciones generadoras y demandantes de información en una dimensión significativa.

En una primera aproximación parecería discutible la idea de un Mercosur de la información, en tanto Internet y el desarrollo de las telecomunicaciones nos han convencido, prima facie, de que no existen límites, barreras o fronteras administrativas nacionales o regionales, para el tráfico de información. La noción de aldea global se ha enquistado entre nosotros y nos transmite la ilusión de que mediante las nuevas tecnologías se han resuelto mágicamente los problemas de acceso a los registros referenciales y a los documentos que contienen la información que necesitamos.

Sin embargo, los documentalistas y profesionales de la información hemos tomado conciencia de que sólo comenzamos a intuir la magnitud y la diversidad de los nuevos problemas que genera la democratización del acceso a fuentes informativas electrónicas. Internet, por vía de ejemplo, ha demostrado ser un maduro sistema de telecomunicaciones, pero un sistema de información precariamente diseñado, sin un control preciso de la calidad y credibilidad de la información que allí se vuelca, con escaso control terminológico, y sin un registro histórico de sus páginas web. Hemos vuelto de alguna manera al reino del lenguaje natural, libre y descontrolado, cuyas virtudes y problemas han sido tratados por décadas y ocupan bibliotecas enteras de bibliotecología y documentación. Cuando no se cuenta con datos específicos para una búsqueda (por ejemplo, la dirección de un sitio o «site»), la sensación que se tiene es que se está buscando un diamante entre la hojarasca, en una lucha desventajosa contra el tiempo. Como señala Coyle (1996, p. 4) «todo se reduce a que si no encontramos la información que necesitamos, entonces no tiene importancia si dicha información existe o no...hay millones de bytes en los archivos de la red que para todo propósito práctico son inexistentes».

Al contrario de estas cuestiones de índole global, estamos convencidos de que existen problemáticas de información propias y específicas del Mercosur. En efecto, nuestra región comprende a cuatro países con culturas e historias diferentes, y a dos grandes comunidades lingüísticas (si hacemos abstracción del guaraní y otras lenguas indígenas de uso restringido). Por otra parte, «el marco político del Mercosur propicia una unión económica que tiene grandes consecuencias sobre el principal instrumento de intercomunicación: la lengua... la lengua coloquial, los lenguajes de especialidades, el lenguaje técnicocientífico, el jurídico, el administrativo, etc.» (Der-Meguerditchian, 1997, p. 1).

La diversidad lingüística y la necesidad de fijar con claridad los términos del intercambio comercial, industrial, científico, 
académico y cultural hacia adentro y hacia afuera del bloque, conllevan la exigencia de patrones, medidas, normas y terminologías comunes. Por tanto, la misma razón de existencia del Mercosur obliga a establecer criterios y reglas de normalización, compatibilización, armonización o correspondencia desde el punto de vista de las lenguas y las áreas de especialidad y de actividad involucradas.

Ahora bien, ¿qué debemos entender en este contexto, por normalización, armonización, compatibilización y correspondencia?

\section{Normalización}

Como hemos escrito en alguna parte (Barité, 1997, p. 96), «la NORMALIZACION refiere al sometimiento de un conjunto de fenómenos, situaciones y objetos a un modelo, reglamento o patrón.» La normalización se expresa actualmente en todo el abanico de actividades humanas especializadas (ciencia, técnica, economía, comercio, industria, etc.), y persigue la identificación precisa y uniforme de productos y procesos, y su reducción a normas de validez teóricamente universal. Por esa vía, se busca la solución padronizada de problemas técnicos y comerciales referentes a productos, bienes y servicios; y la identificación y diferenciación de los mismos por motivos legales, económicos o administrativos.
La normalización requiere consensos internacionales, y organismos con autoridad, que preparen, establezcan, difundan, validen y hagan respetar las normas. Como la Terminología es un problema clave de la comunicación, su presencia es fundamental en el proceso de normalización, porque ¿cómo normalizar algo si no se sabe con exactitud lo que designan las palabras que identifican a ese algo? ¿Cómo alcanzar un consenso técnico si no existe un consenso terminológico previo? Básicamente, pueden ser objeto de normalización los productos y los procesos (especialmente los industriales), las unidades y los símbolos de cálculo y medida, la seguridad de personas y bienes.

El organismo internacional que lidera las actividades de normalización en el mundo es la Organización Internacional de Estandarización (ISO), creado en 1946 para facilitar la unificación y la coordinación internacionales de las normas industriales. Desde 1945 la ISO ofrece regulaciones universales bajo la denominación de NORMAS ISO. Las normas son documentos que recogen los acuerdos y los ámbitos de aplicación entre las partes involucradas, reunidas en una comisión representativa de especialistas.

La ISO actúa mediante Comités Técnicos. En especial nos interesa mencioanr el TC 37, dedicado a la «Terminología (principios y coordinación)», pues se dedica al desarrollo de métodos de elaboración y coordinación de las 
terminologías normalizadas nacionales e internacionales. Algunas normas que han surgido del TC 37 son la ISO 860 (Armonización internacional de los conceptos y términos), y la norma ISO 639 (Código de lenguas).

Existen otros organismos de normalización, complementarios entre sí, de caracter nacional o regional; otros multinacionales que actúan como instituciones de normalización, y aún otros que disponen de unidades propias de normalización, como la Organización Mundial de la Salud o la Organización Internacional del Trabajo. En todos los casos, el objetivo que persiguen es la simplificación, su actividad es establecida por consenso (antes que por imposición), y sus normas son esencialmente revisables.

Lamentablemente, el Mercosur no cuenta con un organismo semejante, y sus necesidades son cubiertas -hasta el momento- a través de la referencia indirecta a las normas generadas por otras instituciones internacionales.

Habrá quien pueda sostener que la formación de un organismo de normalización Mercosur sea innecesario o redundante. Sin embargo, la estandarización o normalización de productos, bienes y terminologías es un proceso complejo que requiere el reconocimiento de la propia identidad de la región. La organización de sistemas de conceptos, la definición y fijación de denominaciones, abreviaturas y símbolos, la creación de nuevos términos, las equivalencias en los dos idiomas, los factores de tipo sociolingüístico (las costumbres y las creencias morales, éticas, idiosincráticas propias de la región), exigen un tratamiento diferencial que implica, en última instancia, el ejercicio de la soberanía regional. Ya que la finalidad de la normalización es favorecer la comunicación, parece lógico que las reglas sean impuestas por sus actores.

¿Qué es lo que debe ser alcanzado por la normalización? Deberíamos distinguir entre normalización de la producción de bienes y servicios y la normalización terminológica. En particular, la normalización de bienes y servicios permite establecer con claridad las especificaciones técnicas de cada producto o proceso, ajustándolas a los estándares internacionales vigentes, lo que asegura el cumplimiento de condiciones mínimas de calidad, funcionamiento y compatibilidad. Complementariamente, la normalización de la terminología relativa a esos productos y procesos, asegura la claridad y la comprensión de los términos del intercambio. Por ello la Terminología, que parece tan lejana a la producción industrial desde su cercanía a la Lingüística, tiene directas implicaciones directas y recíprocas con la ciencia, la tecnología, y los estándares de producción.

En esta era de gerenciamiento, distribución e intercambio de información en alta escala a través de las autopistas informáticas, la normalización de la 
terminología contribuye en varios sentidos: por un lado, es una de las vertientes del proceso de normalización de los productos industriales y comerciales, pues sin comprensión lingüística no hay comunicación. Por otra parte, es una vía directa de acceso y recuperación de información especializada. La Terminología tiene, por ello, aplicaciones en documentación (indización, elaboración de resúmenes, creación de lenguajes controlados), en la redacción técnica y científica, como herramienta fundamental para la traducción especializada, y en los procesos de enseñanza/aprendizaje de disciplinas especializadas, actividades - todas ellas directamente involucradas en el proceso de integración socio-cultural que lentamente acompaña al Mercosur.

La normalización terminológica, al decir de Blanchon (1995, p 17), «lejos de ser un simple fenómeno lingüístico, oculta numerosas rivalidades comerciales, aun cuando ello sea menos evidente a primera vista que en el caso de la normalización técnica.» Los procesos de transferencia de tecnología a gran escala no son neutros ni objetivos. Por el contrario, se sostienen en motivaciones comerciales (competencia, lucro, conquista de mercados) e industriales (control de la propiedad intelectual, de patentes, marcas y diseños). Las empresas de primer nivel pretenden imponer con sus productos su propia terminología. En casos extremos, ello lleva al fenómeno lingüístico de la lexicalización (así en Uruguay, al teléfono celular se lo conoce popularmente 
comités de normalización establecen.

Como los productos tecnológicos requieren pautas específicas de operación y funcionamiento, la segunda venta es la del «know-how», mediante modalidades de contratación de «franchising». El paquete suele incluir las instancias de capacitación.

Naturalmente, con el «know-how» se transfiere la terminología correspondiente tanto a los productos como a su manejo operacional. Por eso suele decirse que cuando se adopta un producto se adopta también su terminología.

La última etapa de este trasiego consiste en la transferencia de los productos informáticos e informativos que requieren el conocimiento y la actualización (acceso oneroso a la información, CD ROM, etc.).

\section{Armonización}

¿Qué entendemos por armonización?. Su significado parece inteligible y sencillo; sin embargo, tiene matices peculiares en lo que hace al proceso de integración regional. Dice el Ferreira (s.d., p. 787) que la HARMONIZAÇAO «é o ato ou efeito de harmonizar-se». Y bajo HARMONIZAR registra en su primera acepción «por em harmonia, tornar harmonico, conciliar, congraçao». Estamos diciendo entonces que la armonización implica la puesta en concierto de objetos o fenómenos que, sin perjuicio de ser desiguales o distintos, tiene ciertos elementos de afinidad o complementariedad que hacen posible esa concertación. Allí hay un rasgo que distingue sustantivamente esta idea de la de normalización.

¿Qué debe armonizarse en el Mercosur? Sin lugar a dudas, las legislaciones nacionales, de modo que puedan ir adecuándose a los preceptos, los acuerdos y la filosofía de integración regional.

La armonización normativa comprende la primera etapa del proceso de armonización, y tiene que ver -por una partecon el establecimiento de las concordancias y correspondencias entre las distintas normas jurídicas (leyes, decretos, etc.) internas de cada país sobre una temática. En segundo término, corresponde a un esfuerzo específico de los congresos o parlamentos de cada Estado miembro, por ajustar las legislaciones internas al espíritu y al texto de los acuerdos regionales. En una tercera etapa de desarrollo posterior, la armonización debería culminar en la elaboración de normativa regional, de eficacia supranacional, y de cumplimiento obligatorio para cada una de las partes. En ese estadio, cercano a un proceso de integración política, será posible concebir la elaboración por un Parlamento regional, de una legislación propia y obligatoria para el Mercosur. 


\section{Compatibilización}

Desde el punto de vista informático, el término «normalización» no siempre es el más feliz, porque la experiencia reciente ha enseñado que mediante interfases adecuadas y amigables puede establecerse la compatibilización entre sistemas de información de estructura diversa. Sólo si se desea establecer una red de comunicación entre esos sistemas parece más adecuado hablar de normalización informática en términos de formatos y programas.

Tradicionalmente ha habido en Latinoamérica escasa integración entre los sectores público y privado. Los Estados suelen estructurarse sobre grandes entramados burocráticos de gran peso dentro de cada país, con escasa coordinación de sus sistemas de información no fiscales o no comerciales. Sus sectores empresariales están estructurados sobre empresas medianas y pequeñas poco estables. El espacio Mercosur no escapa a esa realidad que obstaculiza los procesos de coordinación, interacción y normalización informática.

\section{Correspondencia o equivalencia}

Por último, debemos clarificar los conceptos de equivalencia o correspondencia, que tienen directa relación con el flujo recíproco de conceptos y términos especializados - esto es, terminología- entre las dos comunidades lingüísticas del Mercosur. La equivalencia se define como el término sinónimo, cuasi sinónimo o afín en otro idioma. También designa a la relación que se establece entre dos o más términos procedentes de distintas lenguas, que representan la misma noción (un objeto, un fenómeno o una concepción).

No abundaremos, por economía de tiempo, en la importancia de contar con instrumentos terminológicos seguros, fiables, actualizados en el conjunto de las áreas involucradas por la integración regional, que faciliten la comprensión recíproca de conceptos, ideas y expresiones. Sólo mencionaremos algunos de ellos, señalando que este es un campo todavía inexplotado por los especialistas a nivel del Mercosur: los diccionarios técnicos, los glosarios especializados, los léxicos, las tablas de equivalencias, los tesauros; pero especialmente, los Bancos de Datos Terminológicos, como gigantescos depósitos organizados de terminología técnica, científica, comercial, aduanera o de cualquier otra especie, que contribuyen efectivamente a dinamizar el intercambio, facilitando el trabajo de profesionales de la información, traductores, periodistas, empresarios y gobernantes.

Por ello los grandes bloques o potencias económicas del primer mundo han tenido particular preocupación por desarrollar bancos de datos terminológicos en ciencia y tecnología cuyo volumen alcanza centenares de miles de términos: EURADICATOM (el banco terminológico de la Unión Europea), y TERMIUM (de-

\footnotetext{
Inf.Inf., Londrina, v. 5, n. 1, p. 43-60, jan./jun. 2000
} 
sarrollado en Canadá) son los ejemplos más evidentes de esta preocupación.

En el Mercosur no se ha generado todavía, a nivel de los gobiernos, la conciencia política necesaria en torno a los problemas terminológicos emergentes de la integración, y a la necesidad de organizar un banco de datos terminológicos de gran porte, que justifique la dedicación de recursos para su desarrollo. La convicción existe en el ámbito de los organismos formales o informales que trabajan en cada país, y en forma conjunta, en el ámbito de la Terminología, pero que están alejados de los centros de decisión empresariales y gubernamentales. En estos grupos hay constancia de la preocupación por establecer «la definición de las necesidades terminológicas prioritarias del Mercosur» en concordancia con las exigencias del intercambio internacional; el diseño de un Banco de Datos Terminológico que opere como fuente oficial de validación de términos; la discusión de metodologías para la selección, la colecta y el registro de los datos terminológicos a ser incorporados, y la adopción de un formato común que permita el efectivo intercambio efectivo de datos e informaciones.

\section{POLITICAS DE INFORMACION Y COMUNICACION EN EL MERCOSUR}

No es sencillo responder si existen políticas de información y de comunicación establecidas en el marco del acuerdo regional. Está claro que la misma dinámica de los intercambios económicos ha generado la imperiosa necesidad de instrumentos intermediadores, antes que la discusión de políticas. Desde el punto de vista del intercambio económico, el más importante intermediador es, sin duda, la Nomenclatura Común del Mercosur o NCM, aprobada en Uruguay por decreto de fecha 31 de diciembre de 1996. La NCM fue construída a partir de un Código Internacional de Mercaderías creado en el ámbito del GATT, restringido luego al área de la $A L A D I, y$ reformulado para el Mercosur en códigos de productos y bienes de hasta diez dígitos. La Nomenclatura se aplica a todas las operaciones de comercio exterior y, según surge del decreto uruguayo, se ajusta a «la Enmienda del Sistema Armonizado de Designación y Codificación de Mercaderías (Res. 36/95 del Grupo Mercado Común)» con su correspondiente Arancel Externo Común (AEC).

La NCM abarca el conjunto de mercaderías que caen bajo el arancel externo común, y se organiza por Secciones, Capítulos y Subcapítulos cuyos títulos sólo tienen un valor indicativo. Hay veintiun (21) Secciones que distribuyen mercaderías por tipos; así, la sección I corresponde a Animales vivos y productos del reino animal, y la sección $\mathrm{XI}$ a «Materiales textiles y sus manufacturas». Agrega una lista de abreviaturas y símbolos normalizada para la región, y reglas generales de interpretación.

Cada entrada de la Nomenclatura se 
organiza a partir de un número de ítem y una glosa o descripción del producto. Por ej.:

A) en el capítulo 18 (Cacao y sus preparaciones), tenemos el ítem «1806.31 10» que corresponde a la descripción o glosa «CHOCOLATE»

B) en el capítulo 30 (Productos farmacéuticos), dentro del punto 30.03 MEDICAMENTOS, ubicamos bajo el ítem «3003.90.55» a las descripciones o glosas «PARACETAMOL» $y$ «BROMOPIDA».

Agregada la alícuota, se establece la posición arancelaria de cada producto.

Los órganos del Mercosur también han desarrollado reglamentos técnicos, y otros instrumentos relacionados con cuestiones arancelarias.

Pero lo que realmente no se ha discutido hasta hoy, es lo relativo a la articulación transnacional de los bancos de datos de interés regional, ni las reglas del intercambio de información. Un obstáculo insalvable hasta el presente está dado por el hecho de que esos bancos de datos se desarrollan bajo responsabilidad de instituciones no gubernamentales y universidades, que no han sido hasta el presente los actores centrales en este proceso. Las profesiones involucradas tampoco han participado en las instancias de debate y acuerdo. Sin embargo, como apunta Delpiano (1998, p. 356), «comienza a vislumbrarse la posibilidad, y la necesidad de crear bases y bancos de datos regionales, con sede en uno o más países del Mercosur, que colecten información de todos ellos, centralizándola (virtualmente) para su procesamiento, provocando luego el retorno de la información a los interesados de todo el mercado común.»

Es probable que los primeros bancos regionales de datos sean los comerciales, especialmente aquellos que proporcionan información sobre la situación crediticia, patrimonial o comercial de las personas. Esto se anticipa por el profundo debate que se procesa actualmente en doctrina jurídica, respecto a eventuales invasiones a los derechos de privacidad y las maneras de contrarrestarla (el habeas data, etc.).

En cuanto a la regulación de la conexión de sistemas y del intercambio de información, existe un Uruguay un antecedente que podría ser usado como modelo por el sistema regional: un Acuerdo Marco de Cooperación del año 1991 otorgado por la República del Uruguay y la Comunidad Económica Europea. Allí se establece como forma de cooperación económica el intercambio continuo de información, en especial mediante la conexión de bancos de datos ya existentes o la creación de otros nuevos.

Está claro que la información constituye un bien de naturaleza intangible, pero valuable y comercializable, y pasible de procesos de valor agregado a partir de la ejecución sobre la misma de diversos

Inf.Inf., Londrina, v. 5, n. 1, p. 43-60, jan./jun. 2000 
procesos intelectuales o automáticos. Siendo un bien, está protegido por ende, por el principio de libre circulación de bienes, servicios y factores productivos en el Mercosur. En consecuencia, no existen a priori dificultades mayores para su transferencia. Pero esa aspiración es hoy más virtual que real porque, por una parte, requeriría el cumplimiento efectivo de todos los procesos de normalización, armonización, compatibilidad y correspondencia de que hemos venido hablando. Por otra parte, existen otros aspectos vinculados a los derechos de autor y de propiedad intelectual que están en plena discusión respecto a los bienes informáticos y de información.

\section{CONCLUSIONES Y RECOMENDACIO-} NES

Si bien es cierto que parte de los problemas que se han suscitado en el Mercosur tienen por causa intereses económicos o políticos contrapuestos, no es menos acreditado que otros problemas se han suscitado por la falta de entendimiento, por la ausencia de traducciones conceptuales y no meramente literales de textos y documentos, por las dificultades para definir técnicamente mercancías y productos de modo unívoco, y por la ausencia de bancos de datos y sistemas de información regional en efectiva interrelación.

La Terminología está en condiciones de contribuir a solucionar algunas cuestiones lingüísticas. Así, puede servir como elemento de regulación e intercambio entre las lenguas oficiales del bloque, el español y el portugués. A medida que se desarrolle el espacio Mercosur habrá un aumento natural de las necesidades y las demandas de terminología bilingüe en ambos idiomas, así como de sistemas de correspondencia con el idioma inglés, que en materia de tecnología y ciencia es el idioma director.

La ausencia de bancos de datos y sistemas de información regional en efectiva interrelación, la dificultades para establecer políticas nacionales y regionales de información a largo plazo; la carencia de inventarios actualizados de recursos informacionales; la dispersión y superposición de programas y proyectos en el área; la irrelevante inversión informática en los centros educativos de nivel primario y secundario, son nudos problemáticos centrales en la toma de decisiones políticas, geopolíticas, económicas, sociales y culturales.

Por lo expuesto, nos permitimos formular las siguientes recomendaciones:

- favorecer la integración de los sistemas de información nacionales y regionales, mediante el establecimiento de redes temáticas regionales a cargo de instituciones que desarrollan sus actividades en áreas comunes o afines.

- crear un Comité Informático Regional en la órbita del Mercosur que permita compatibilizar o normalizar los programas informáticos 
existentes, y que establezca pautas generales para asegurar la efectiva intercomunicación y el acceso a todas las fuentes de información.

- designar un Comité Mercosur de Normalización, que contribuya a resolver los problemas de definición técnica y caracterización de bienes de producción y servicios.

- fomentar la creación y el desarrollo de bancos de datos terminológicos o de información en áreas prioritarias para el Mercosur, con apoyo financiero de los sectores oficiales y privados beneficiados.

- apoyar la publicación impresa o electrónica de directorios, listas de «sites», diccionarios, glosarios y léxicos bilingües en portugués y español, con objeto de asegurar una cobertura regional de publicaciones secundarias o referenciales.

- favorecer la enseñanza del otro idioma en los países del Mercosur.

- propender a la formación interdisciplinaria en Terminología dentro de las Universidades de la región, asegurando la participación de los profesionales especialmente interesados (lingüistas, informáticos, documentalistas, traductores y especialistas de cualquier dominio cuyo centro de actividad sea la información).

\section{BIBLIOGRAFÍA}

BARITÉ, Mario. Glosario de organización y representación del conocimiento: clasificación, indización, terminología. Montevideo : Comisión Sectorial de Investigación Científica, 1997. 170 p.

BEZERRA, Carlos Alberto Mendes, THIAGO, Eduardo Campos de São. O Mercosul e as normas técnicas. Ci. Inf., Brasilia, v. 22, n. 1, p. 68-70, jan./abr. 1993.

BLANCHON, Elisabeth. ¿Quién le teme a la normalización? Terminómetro, n. 17, p. 15-17, feb. 1995.

COYLE, Karen. Access: not just wires. [en línea] Oct. $1994 \quad<$ http:// w w w. d I a . u cop.ed u / ke c / njwspan.html>[Consulta: 26 mayo 1998].

CUNHA, Murilo Bastos da, ROBREDO, Jaime. Necesidade de integraçao das políticas de informaçao no Mercosul. Ci. Inf., Brasilia, v. 22, n. 1, p. 7-12, jan./abr. 1993.

DELPIANO, Héctor Miguel, DUBIÉ, Pedro. Bancos de datos comerciales en el Mercosur. In: Congreso Iberoamericano de Derecho e Informática, 6. Ponencias. Montevideo : IMPO, 1998. p. 341-361.

DER-MEGUERDITCHIAN, Silvina. Perfil terminológico de los conceptos jurídicos empleados en el Tratado de Asunción: propuestas para una redacción normativa. Berlín : Universidad Humboldt, 1997. Tesis.

DROMI, Roberto. Código Mercosur: Protocolos, Acuerdos, Declaraciones, Decisiones, Resoluciones, Directivas. Buenos Aires : FCEA, 1996. 
FAYARD, Pierre-Marie. Crecimiento de la especialización versus comunidad: el proyecto histórico, político y estratégico de la comunicación pública de la ciencia y la tecnología. Quark, n. 8, p. 47-51, jul./ set. 1997.

FERREIRA. Aurélio Buarque de Hollanda. Novo dicionário de língua portuguesa. Rio de Janeiro : Nova fronteira, s.d

GALINSKI, Christian. Terminology: towards clarity. ISO Bull., v. 26, n. 1, jan. 1995.

KLOR, Adriana Dreysin de. Sistema de solución de controversias en el Mercosur. In: MERCOSUR: balance y perspectivas. Montevideo : FCU, 1996. p. 83-101.

KRIEGER, Maria da Graça. Terminología para o Mercosul. In: SIMPOSIO IBEROAMERICANO DE TERMINOLOGIA RITERM: Terminología y desarrollo, 4, 1994, Buenos Aires. p. 115-117.

MELLADO, Noemi. El Mercosur en el contexto político y económico internacional y latinoamericano. In: MERCOSUR: balance y perspectivas. Montevideo : FCU, 1996. p. 158-170.

MERCOSUR: tratados y anexos. Montevideo : Asociación de Escribanos del Uruguay, 1991. 28 p.

MINISTERIO DE EDUCACIÓN Y CULTURA DEL URUGUAY. Dirección de Educación. Recopilación de los principales documentos del Mercosur educativo. Montevideo, 1996. (Serie Educación y Mercosur).

PROYECTO de banco de datos terminológico para el Mercosur : BDT Uruguay : III versión / URUTERM. Montevideo : Uruterm, 1996.
REILLY, Marcelo Bauzá et al. El régimen general de origen de productos en el Tratado de Asunción (Mercosur): un análisis juri-lingüístico. In: Congreso Iberoamericano de Derecho e Informática, 6. Ponencias. Montevideo : IMPO, 1998. p. 327-331.

URUGUAY. Poder Executivo. Nomenclatura Común del Mercosur (NCM) aprobada por la resolución n³6/995 del Grupo Mercado Común : decreto 511/996. Montevideo: Dirección Nacional de Impresiones y Publicaciones Oficiales, 1996.

VIGNALI, Heber Arbuet. El Protocolo de Ouro Preto: una excusa para hablar de integración. In: MERCOSUR: balance y perspectivas. Montevideo : FCU, 1996. p. 33-40. 


\section{Mario Barité}

Escribano y Licenciado en Bibliotecología. Director de la Escuela Universitaria de Bibliotecología de la Universidad de la República, Montevideo, Uruguay. Docenteinvestigador en las áreas de «Clasificación» y «Terminología».

\section{Title}

The Normalization, Harmonization, and Compatibility Processes in "Mercosul":impacts in the Field of Information

\section{Abstracts}

This article characterizes and summarizes the existence of "Mercosul" up to the present and discusses the idea of a "Mercosul of Information", which comprises aspects of the policies related to transfer, interchange, and access to information. It also determines the concept of "normalization" in the project of economical, political, social, and cultural integration, implicit in the creation and development of "Mercosul", and analyzes such concept in light of the notions of "harmonization", "compatibility", "correspondence", and "equivalence". Then it deals with the production of goods and of information services, as well as the possible ways to integrate information policies, systems, and nets. It emphasizes the contribution of terminology as a fundamental tool in the interaction of issues such as commerce, industry, science, and culture involved in the regional development. It eventually suggests recommendations to the development of regional information policies.

\section{Keywords}

Normalization Information Transfer; Access to Information; Mercosul; Terminology

\section{Título}

Os Processos de Normalização, Harmonização e Compatibilização no Mercosul: impactos no setor informação

\section{Resumen}

Caracteriza y reseña la existencia del Mercosur hasta el presente, y en particular discute la idea de un "Mercosur de la información" que comprenda aspectos de políticas de transferencia, intercambio y acceso a la información. Determina el concepto de "normalización" en el marco del proyecto de integración económica, política, social y cultural implícito en la creación y el desarrollo del MERCOSUR, y lo analiza con las nociones de "armonización", "compatibilización", "correspondencia" y "equivalencia". Discurre sobre la producción de bienes y servicios de información, y sobre las modalidades posibles de integración de políticas, sistemas y redes de información. Destaca el aporte de la Terminología como instrumento de primera orden para interactuar en las cuestiones de comercio, industria, ciencia y cultura involucradas en el desarrollo regional. Por último, propone recomendaciones que puedan contribuir al desarrollo de políticas regionales de información.

\section{Palabras-Clave}

Normalización; Transferencia de Información; Acceso a la Información; Mercosur; Terminología.

Artigo recebido em: 30/04/98 